\title{
Proteoglycan 4 is a diagnostic biomarker for COPD
}

This article was published in the following Dove Press journal:

International Journal of COPD

18 September 2015

Number of times this article has been viewed

\author{
Kang-Yun Lee ${ }^{1,2}$ \\ Hsiao-Chi Chuangl,3 \\ Tzu-Tao Chen' \\ Wen-Te Liu'1,3 \\ Chien-Ling Su ${ }^{1,3}$ \\ Po-Hao Feng ${ }^{1,2}$ \\ Ling-Ling Chiang 1,3 \\ Mauo-Ying Bien ${ }^{3,4}$ \\ Shu-Chuan $\mathrm{Ho}^{3}$
}

'Division of Pulmonary Medicine, Department of Internal Medicine, Shuang Ho Hospital, Taipei Medical University, New Taipei City, Taiwan ${ }^{2}$ Department of Internal Medicine, School of Medicine, ${ }^{3}$ School of Respiratory Therapy, College of Medicine, Taipei Medical University, Taipei, Taiwan; ${ }^{4}$ Division of Pulmonary Medicine, Department of Internal Medicine, Taipei Medical University Hospital, Taipei Medical University, Taipei, Taiwan
Correspondence: Shu-Chuan Ho School of Respiratory Therapy, College of Medicine, Taipei Medical University, 250 Wuxing Street, Taipei I I0, Taiwan Tel +88622736 I66I ext $35 \mid 2$

Fax +886 22739 I I 43

Email shu-chuan@tmu.edu.tw
Introduction: The measurement of C-reactive protein (CRP) to confirm the stability of COPD has been reported. However, CRP is a systemic inflammatory biomarker that is related to many other diseases.

Objective: The objective of this study is to discover a diagnostic biomarker for COPD. Methods: Sixty-one subjects with COPD and 15 healthy controls (10 healthy non-smokers and 5 smokers) were recruited for a 1-year follow-up study. Data regarding the 1-year acute exacerbation frequency and changes in lung function were collected. CRP and the identified biomarkers were assessed in the validation COPD cohort patients and healthy subjects. Receiver operating characteristic values of CRP and the identified biomarkers were determined. A validation COPD cohort was used to reexamine the identified biomarker. Correlation of the biomarker with 1-year lung function decline was determined.

Results: Proteoglycan 4 (PRG4) was identified as a biomarker in COPD. The serum concentrations of PRG4 in COPD Global initiative for chronic Obstructive Lung Disease (GOLD) stages $1+2$ and 3+4 were $10.29 \mathrm{ng} / \mathrm{mL}$ and $13.20 \mathrm{ng} / \mathrm{mL}$, respectively; $4.99 \mathrm{ng} / \mathrm{mL}$ for healthy controls $(P<0.05)$; and $4.49 \mathrm{ng} / \mathrm{mL}$ for healthy smokers $(P<0.05)$. PRG4 was more sensitive and specific than CRP for confirming COPD severity and acute exacerbation frequency. There was no correlation between CRP and PRG4 levels, and PRG4 was negatively correlated with the 1 -year change in predicted forced vital capacity percent $\left(R^{2}=0.91, P=0.013\right)$.

Conclusion: PRG4 may be a biomarker for identification of severity in COPD. It was related to the 1-year forced vital capacity decline in COPD patients.

Keywords: C-reactive protein, exacerbation, inflammation, lung function decline

\section{Introduction}

COPD is characterized by a progressive loss of lung function that is caused by consistent or repeated inflammatory responses in the lungs. ${ }^{1}$ The pulmonary inflammation that occurs in small airways and pulmonary tissues often results in systemic inflammation. ${ }^{1}$ COPD is heterogeneous, with wide variations in the rate of lung function decline, extent of emphysema, frequency of acute exacerbations (AEs), intensity of respiratory symptoms, and presence of systemic effects. C-reactive protein (CRP) is commonly used to assess several acute clinical conditions, including COPD. ${ }^{2}$ However, CRP levels are elevated in many conditions, ${ }^{3-5}$ and the relevance of a high CRP level in a particular disease is often inadequately defined.

Proteoglycan 4 (PRG4) has several distinct biological functions, including immunoreactivity, cytoprotection, lubrication, and matrix binding. ${ }^{6-8}$ PRG4 is also expressed in many tissues/organs, including the lungs, heart, liver, bone, and cartilage, ${ }^{8}$ and can be detected in blood and urine. ${ }^{9,10}$ Proteoglycans are produced by most eukaryotic cells, and they have many disease-related forms and functions in the human body. ${ }^{11}$ For example, Hallgren et al observed that fibroblasts from COPD patients have 
alterations in proteoglycan production that could relate to the development of pulmonary disease. ${ }^{12}$ Proteoglycans provide structural support and impart biomechanical properties to the lung tissue, and they are an important biological mediator in the regulation of lung inflammation, homeostasis, and wound healing. ${ }^{13}$

This study identified and assessed the use of serum biomarkers compared with CRP to confirm COPD and AEs. We performed a comprehensive screening of protein profiles in healthy subjects and patients with Global initiative for chronic Obstructive Lung Disease (GOLD) stages 1, 2, 3, and 4 COPD using a proteomic approach. The identified protein candidates were determined in serum samples from two COPD groups for biomarker selection and validation. We also collected previous 1-year AE frequency and lung function data. The receiver operating characteristic (ROC) curve values of CRP and PRG4 and their correlation with 1-year lung function decline were determined.

\section{Materials and methods Ethics}

The Ethics Committee of Taipei Medical University-Joint Institutional Review Board (Taipei, Taiwan) approved the study protocol. All subjects received written and oral information prior to inclusion and provided written informed consent.

\section{Study population for biomarker selection}

We examined 61 patients with COPD and 15 subjects without COPD in Shuang Ho Hospital (New Taipei City) in Taiwan between January 2013 and October 2014. All of the subjects were aged 40-80 years at the time of inclusion. Subjects with known cancer, active inflammatory disease (such as asthma, bronchiectasis, and other non-COPD-related disease), or an exacerbation during the 4 weeks prior to the study were not included. All of the patients with COPD received the diagnosis from a physician and exhibited a post-bronchodilation forced expiratory volume in the first second $\left(\mathrm{FEV}_{1}\right)$ /forced vital capacity (FVC) ratio of $<70 \%$. Subjects without COPD exhibited an $\mathrm{FEV}_{1} / \mathrm{FVC}$ ratio of $\geq 75 \%$ and $\mathrm{FEV}_{1} \geq 80 \%$ of the predicted value. Subjects who smoked at the time of recruitment were considered smokers ( $\geq 3$ months of current smoking). Subjects who had never smoked were classified as nonsmokers.

\section{Data collection}

The study physician performed a physical examination of all participants and a clinical interview regarding smoking habits, AEs in the past year, comorbidities, and medical use. The classification of COPD severity followed the GOLD guidelines. ${ }^{1}$ No subject had an AE ( $\leq 4$ weeks) or had received oral corticosteroids ( $\geq 3$ months) prior to the study, and all of the subjects continued with a stable regimen of medications throughout the study. Lung function parameters were assessed at the beginning of recruitment and at a 1-year follow-up visit using a Vitalograph Spirotac VTM. Post-bronchodilation $\mathrm{FEV}_{1}$ and $\mathrm{FVC}$ were measured, and $\mathrm{FEV}_{1} / \mathrm{FVC}$ was calculated. Weight and height were measured using standard methods. Body weight was measured to the nearest $0.1 \mathrm{~kg}$ with the subjects standing barefoot and wearing light indoor clothing. Height was measured to the nearest $0.1 \mathrm{~cm}$. BMI was calculated in $\mathrm{kg} / \mathrm{m}^{2}$. Serum samples were obtained at a 1 -year follow-up visit and stored at $-80^{\circ} \mathrm{C}$ for laboratory measurements.

\section{Protein digestion}

Serum samples from five subjects in the same group were randomly selected and pooled together following protein digestion, ${ }^{14}$ yielding the following samples: healthy controls and COPD GOLD stages 1, 2, 3, and 4. A detailed description of the protein digestion and preparation processes was provided previously. ${ }^{15}$

\section{Mass spectrometry and protein identification}

Tryptic peptides were analyzed using a Thermo LTQ Orbitrap XL mass spectrometer (Thermo Fisher Scientific, Waltham, MA, USA) coupled with an Ultimate 3000 RSLC system (Dionex, Sunnyvale, CA, USA). The conditions for peptide separation and full mass spectrometry scans were reported previously. ${ }^{15}$ The MS raw data were processed into peak lists using Proteome Discoverer 1.4 for Mascot database search with the National Center for Biotechnology Information and UniProt database prediction and a literature search.

\section{Enzyme-linked immunosorbent assay}

Enzyme-linked immunosorbent assays (ELISAs) determined the serum levels of CRP (PDCRP00; R\&D Systems, Inc., Minneapolis, MN, USA) and PRG4 (MBS705095; MyBioSource, San Diego, CA, USA) according to the manufacturers' instructions.

\section{Study population for PRG4 validation}

We examined 46 patients with COPD and 33 subjects without COPD in the same medical center in Taiwan between January 2014 and January 2015. All of the subjects were aged 40-80 years, and the same inclusion and exclusion criteria were used for this population as for the study population for biomarker selection. All of the patients with COPD received the diagnosis from a physician and exhibited a 
post-bronchodilation $\mathrm{FEV}_{1} / \mathrm{FVC}$ ratio of $<70 \%$. The subjects without COPD exhibited an $\mathrm{FEV}_{1} / \mathrm{FVC}$ ratio of $\geq 75 \%$ and $\mathrm{FEV}_{1} \geq 80 \%$ of the predicted value. Serum samples were collected for PRG4 determination using ELISA.

\section{Statistical analysis}

The data are expressed as the means \pm standard deviations. For comparisons among multiple values, one-way analysis of variance with Tukey's post hoc test was used. ROC curve analysis was used to determine the specificity and sensitivity of CRP and PRG4 in COPD. The Youden index was used to determine cutoff values. Pearson's correlation coefficient was used to examine the correlation of PRG4 with CRP. Linear regression was used to examine the correlation of the quintiles of CRP and PRG4 with a 1-year change in predicted $\mathrm{FEV}_{1} \%$, $\mathrm{FVC} \%$, and $\mathrm{FEV}_{1} / \mathrm{FVC} \%$. Statistical analyses were performed using MedCalc statistical software version 15.2.2 (MedCalc Software bvba, Ostend, Belgium) for Windows. The level of significance was set to $P<0.05$.

\section{Results}

\section{Characteristics of the study population for biomarker selection}

Sixty-one subjects with COPD (19 for GOLD stages 1+2 and 42 for GOLD stages $3+4$ ) were included, and ten healthy control and five healthy smoking volunteers were enrolled and followed-up for 1 year. Detailed baseline characteristics of the 76 subjects in the study population are presented in Table 1.

\section{Selection of potential biomarkers in patients with COPD}

Overlaps in protein profiles between healthy controls and COPD GOLD stages $1,2,3$, and 4 were compared to investigate protein expression in COPD (Figure 1A). A total of 180 proteins were identified in the healthy controls, and 199, 191, 186, and 176 proteins were identified in the patients with COPD GOLD stages 1, 2, 3, and 4, respectively (Table S1). A total of 40, 31, 22, and 12 proteins were unique to the patients with COPD GOLD stages 1,2, 3 , and 4 , respectively. These unique proteins from patients with COPD GOLD stages 1, 2, 3, and 4 were further examined, and PRG4, type I cytoskeletal 16 keratin, and type II cytoskeletal $6 \mathrm{~A}$ keratin were commonly present in the COPD serum samples (Figure 1B).

\section{Serum levels of CRP and PRG4}

There was no difference in CRP between the healthy controls $(0.77 \pm 0.22 \mathrm{mg} / \mathrm{L} ; 95 \%$ confidence interval [CI]: $0.50-1.14)$ and healthy smokers $(1.06 \pm 0.67 \mathrm{mg} / \mathrm{L} ; 95 \%$ CI: 0.23-1.89). Generally, the CRP levels of COPD GOLD stages $1+2(4.36 \pm 5.33 \mathrm{mg} / \mathrm{L}$, range $0.56-19.08 \mathrm{mg} / \mathrm{L} ; 95 \%$ CI: $-1.14-9.97)$ and $3+4(5.20 \pm 4.62 \mathrm{mg} / \mathrm{L}$, range $0.33-16.61$ $\mathrm{ng} / \mathrm{mL}$; 95\% CI: $-2.36-14.29)$ were significantly higher than those of the healthy controls $(P<0.05)$ (Figure 2A), but no significant difference in CRP was observed between the healthy smokers and the COPD patients with GOLD $1+2$ and $3+4$. The CRP levels in COPD patients with GOLD $3+4$ were slightly higher than those in patients with GOLD $1+2$, but the difference was not significant. Additionally, the CRP level was associated with COPD with a previous 1 -year frequency of both $\mathrm{AEs}=0$ and $\mathrm{AEs} \geq 1$ compared with healthy controls and smokers (Figure 2B). We observed that the levels of CRP in patients with COPD with AEs $=0$ and AEs $\geq 1$ were $4.10 \pm 3.08 \mathrm{mg} / \mathrm{L}$ (range $0.64-9.77 \mathrm{mg} / \mathrm{L}$; 95\% CI: $-0.39-8.22$ ) and $6.02 \pm 7.07 \mathrm{ng} / \mathrm{mL}$ (range $0.33-$ $19.08 \mathrm{ng} / \mathrm{mL} ; 95 \% \mathrm{CI}:-1.30-12.52)$, respectively, which

Table I Baseline characteristics of the healthy control subjects, healthy smokers, and COPD patients with GOLD stages I+2 and $3+4$ for the biomarker selection study population

\begin{tabular}{|c|c|c|c|c|}
\hline Categorical variables & $\begin{array}{l}\text { Healthy controls } \\
(n=10)\end{array}$ & $\begin{array}{l}\text { Healthy smokers } \\
(n=5)\end{array}$ & $\begin{array}{l}\text { GOLD I+2 } \\
(n=19)\end{array}$ & $\begin{array}{l}\text { GOLD } 3+4 \\
(n=42)\end{array}$ \\
\hline Age, years & $67.8 \pm 6.2$ & $59.8 \pm 14.6$ & $72.4 \pm 7.5$ & $70.0 \pm 8.9$ \\
\hline Men, \% & 75 & 75 & 100 & 93 \\
\hline $\mathrm{BMI}, \mathrm{kg} / \mathrm{m}^{2}$ & $22.5 \pm 2.9$ & $24.8 \pm 4.0$ & $24.6 \pm 2.9$ & $23.5 \pm 3.8$ \\
\hline Current smoking, \% & 0 & 100 & 21 & 17 \\
\hline I-year frequency of AEs (number of patients) & 0 & 0 & $0.4(6)$ & $0.6(15)$ \\
\hline $\mathrm{FEV}_{1}, \%$ predicted & $88.0 \pm 11.5$ & $85.5 \pm 14.9$ & $61.4 \pm 7.8$ & $35.0 \pm 12.2$ \\
\hline $\mathrm{I}$-year change of $\mathrm{FEV}_{1}, \%$ predicted & ND & ND & $-4.5 \pm 25.1$ & $-4.5 \pm 9.6$ \\
\hline FVC, \% predicted & $86.8 \pm 15.6$ & $80.6 \pm 7.9$ & $79.4 \pm 15.5$ & $59.8 \pm 15.6$ \\
\hline I-year change of FVC, \% predicted & ND & ND & $-2.1 \pm 20.7$ & $-3.9 \pm 20.2$ \\
\hline $\mathrm{FEV}_{\mathrm{I}} / \mathrm{FVC}, \%$ predicted & $79.8 \pm 4.8$ & $77.9 \pm 1.8$ & $56.4 \pm 8.2$ & $44.7 \pm 8.7$ \\
\hline I-year change of $\mathrm{FEV}_{1} / \mathrm{FVC}, \%$ predicted & ND & ND & $-6.3 \pm 8.2$ & $-2.8 \pm 7.4$ \\
\hline
\end{tabular}

Note: Data are presented as mean \pm standard deviation.

Abbreviations: AE, acute exacerbation; BMI, body mass index; FEV , forced expiratory volume in the first second; FVC, forced vital capacity; GOLD, Global initiative for chronic Obstructive Lung Disease; ND, no data. 
A
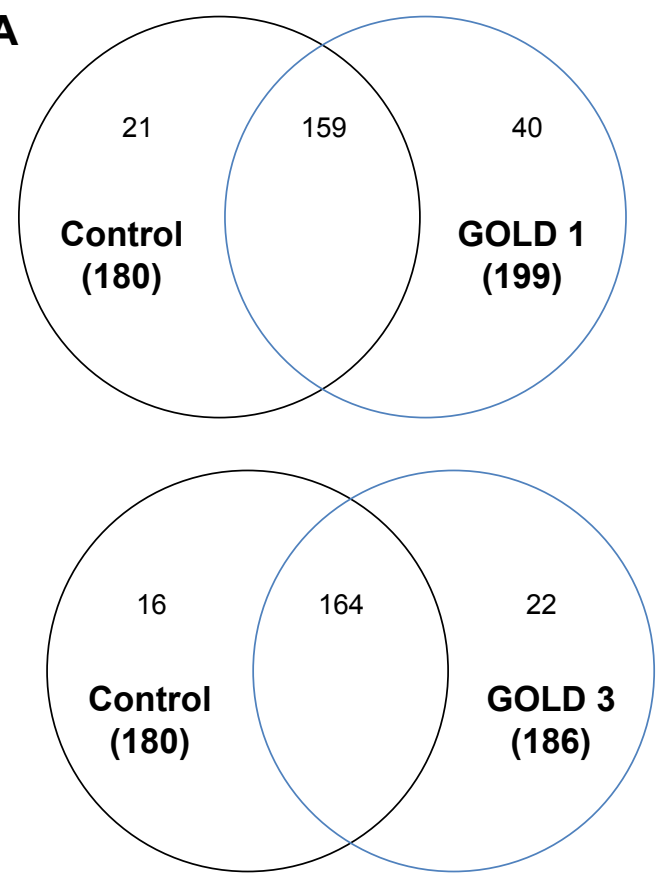
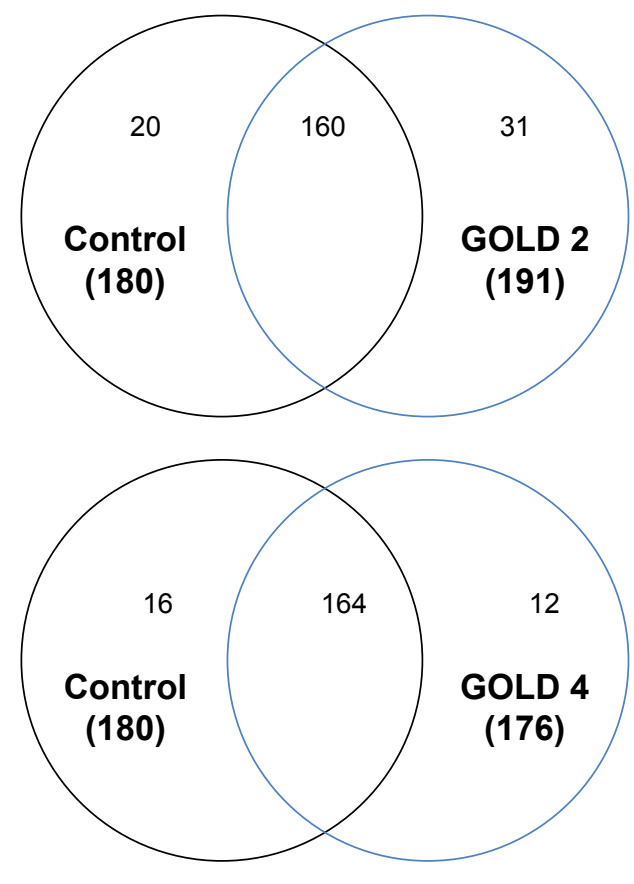

B

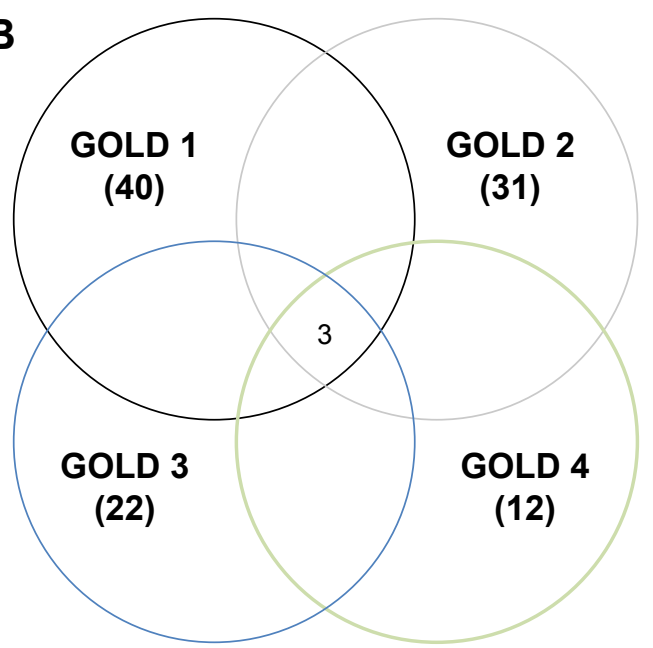

Figure I Venn diagrams showing (A) common among or unique to patients with COPD GOLD stages I, 2, 3, and 4 compared with the healthy controls and (B) common among patients with COPD GOLD stages I, 2, 3, and 4.

Abbreviation: GOLD, Global initiative for chronic Obstructive Lung Disease.

were significantly higher than those in healthy controls $(P<0.05)$. Only COPD patients with AEs $=0$ had higher CRP levels than healthy smokers $(P<0.05)$. The CRP levels in COPD patients with GOLD stages $3+4$ were slightly higher than those in patients with GOLD stages $1+2$, but the difference was not significant.

Figure 2C shows the PRG4 expression in COPD patients with GOLD stages $1+2$ and $3+4$ and healthy controls and smokers. There was no difference in PRG4 between the healthy control $(4.99 \pm 2.01 \mathrm{ng} / \mathrm{mL} ; 95 \% \mathrm{CI}: 1.58-8.23)$ and healthy smoker $(4.49 \pm 2.27 \mathrm{ng} / \mathrm{mL}$; $95 \% \mathrm{CI}: 1.67-7.31)$ groups. The PRG4 levels of COPD patients with GOLD stages $1+2$ and $3+4$ were significantly higher than those of the healthy control and healthy smoker groups $(P<0.05)$, which were $10.29 \pm 3.86 \mathrm{ng} / \mathrm{mL}$ (range $2.5-15.2 \mathrm{ng} / \mathrm{mL} ; 95 \% \mathrm{CI}$ : $1.94-8.90$ ) and $13.20 \pm 3.54 \mathrm{ng} / \mathrm{mL}$ (range $7.0-21.1 \mathrm{ng} / \mathrm{mL}$; 95\% CI: 6.49-8.74), respectively. The COPD GOLD stages $3+4$ subjects had statistically higher levels of PRG4 compared with the COPD GOLD stages $1+2$ subjects $(P<0.05)$. PRG4 expression was divided into two AE-based groups ( $\mathrm{AEs}=0$ and $\mathrm{AEs} \geq 1$ ) of COPD patients, healthy controls, and smokers (Figure 2D). The PRG4 levels in COPD patients with AEs $=0$ and AEs $\geq 1$ were significantly higher than those of the healthy control and smoker groups $(P<0.05)$, which were $10.72 \pm 3.91 \mathrm{ng} / \mathrm{mL}$ (range $2.5-17.2 \mathrm{ng} / \mathrm{mL}$; 95\% CI: $12.03-14.49$ ) and $13.07 \pm 3.64 \mathrm{ng} / \mathrm{mL}$ (range 

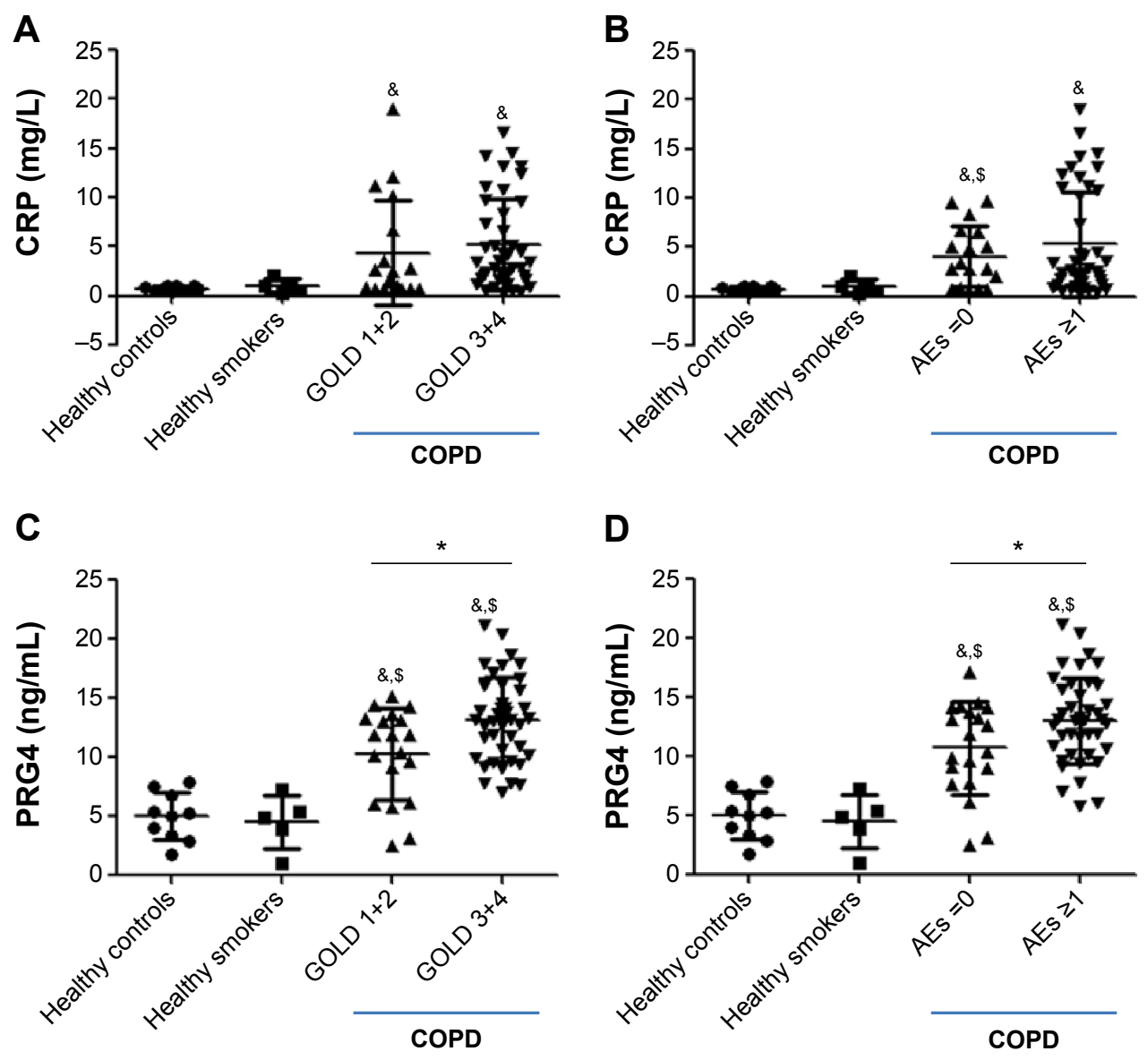

Figure 2 CRP and PRG4 in COPD and COPD with AE.

Notes: (A) Serum CRP levels in healthy controls, healthy smokers, and subjects with COPD GOLD stages I+2 and 3+4. (B) Serum CRP levels in healthy controls, healthy smokers, and COPD patients with $A E s=0$ and AEs $\geq I$. (C) Serum PRG4 levels in healthy controls, healthy smokers, and subjects with COPD GOLD stages I+2 and $3+4$. (D) Serum PRG4 levels in healthy controls, healthy smokers, and COPD patients with $A E s=0$ and $A E s \geq 1$. ${ }^{\&} P<0.05$ compared with healthy controls; ${ }^{\$} P<0.05$ compared with healthy smokers; $* P<0.05$ between groups.

Abbreviations: AE, acute exacerbation; GOLD, Global initiative for chronic Obstructive Lung Disease; CRP, C-reactive protein; PRG4, Proteoglycan 4.

5.8-21.1 ng/mL; 95\% CI: 10.05-18.63), respectively. COPD patients with AEs $\geq 1$ in the previous year had higher PRG4 levels compared with patients with AEs $=0$ $(P<0.05)$.

Figure 3 shows the ROC curve of the sensitivity and specificity of CRP and PRG4 levels for discriminating between the COPD and control groups. The area under the curve value for CRP was 0.850 (95\% CI: 0.765-0.936, $P<0.05$ ), and the area under the curve for PRG4 was 0.953 (95\% CI: $0.908-0.998, P<0.05$ ). The PRG4 cutoff value determined by the Youden index for the control and COPD subjects was $7.892 \mathrm{ng} / \mathrm{mL}$.
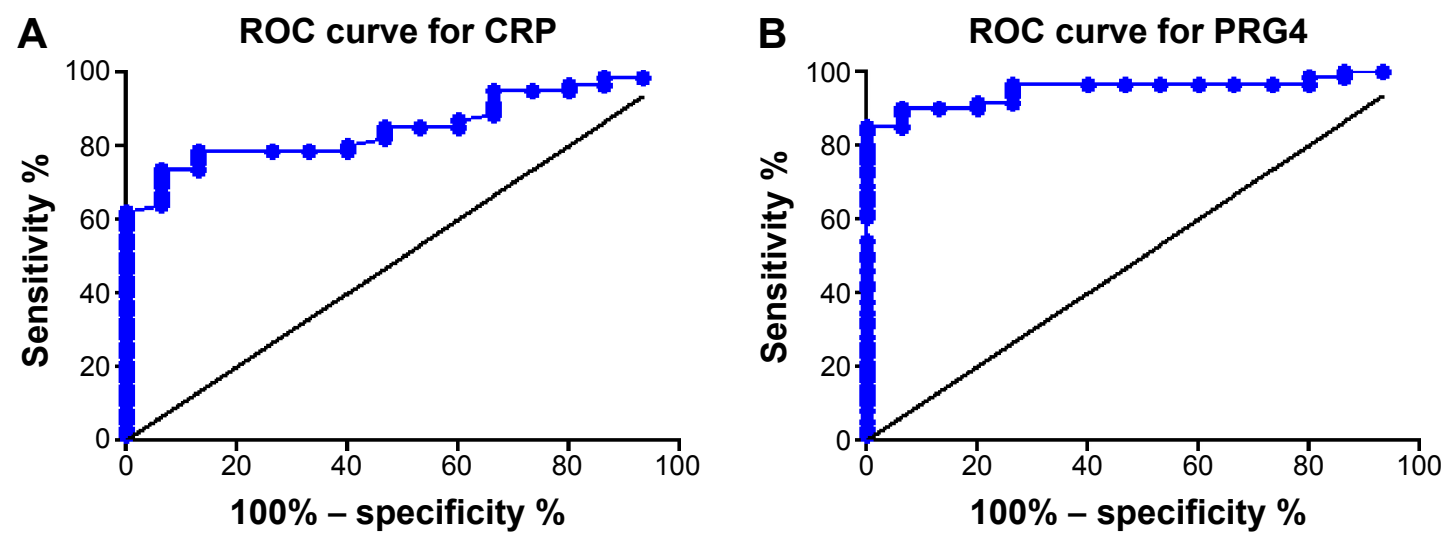

Figure 3 Performance of serum (A) CRP and (B) PRG4 in the ROC curve analyses in COPD.

Abbreviations: ROC, receiver operating characteristic; CRP, C-reactive protein; PRG4, Proteoglycan 4. 
Table 2 Baseline characteristics of the healthy control subjects and COPD patients with GOLD stages I+2 and $3+4$ for the PRG4 validation study population

\begin{tabular}{llll}
\hline Categorical variables & Healthy controls $(\mathbf{n}=\mathbf{3 3})$ & GOLD I+2 $(\mathbf{n}=\mathbf{3 0})$ & GOLD 3+4 $(\mathbf{n}=\mathbf{1 6})$ \\
\hline Age, years & $59.7 \pm 8.6$ & $65.4 \pm 7.6$ & $65.4 \pm 10.5$ \\
Men, \% & 24 & 93 & $8 \mathrm{I}$ \\
BMI, kg/m & $23.7 \pm 2.9$ & $22.9 \pm 3.7$ & $22.5 \pm 3.9$ \\
Current smoking, \% & 0 & 30 & 31 \\
FEV,$\%$ predicted & $87.9 \pm 12.4$ & $68.0 \pm 10.0$ & $38.2 \pm 10.0$ \\
FVC, \% predicted & $86.5 \pm 10.3$ & $78.4 \pm 16.9$ & $58.3 \pm 16.6$ \\
FEV $/$ FVC, \% predicted & $78.9 \pm 5.1$ & $68.0 \pm 9.3$ & $53.6 \pm 9.0$ \\
\hline
\end{tabular}

Note: Data are presented as mean \pm standard deviation.

Abbreviations: BMI, body mass index; FEV , forced expiratory volume in the first second; FVC, forced vital capacity; GOLD, Global initiative for chronic Obstructive Lung Disease; PRG4, Proteoglycan 4.

\section{PRG4 validation for COPD}

Forty-six subjects with COPD (30 for GOLD stages $1+2$ and 16 for GOLD stages $3+4$ ) and 33 healthy controls were enrolled in the PRG4 validation study for COPD. Detailed baseline characteristics of the 79 subjects in the study population are presented in Table 2. The PRG4 cutoff value of $7.892 \mathrm{ng} / \mathrm{mL}$ was used to validate the accuracy of COPD. The detailed diagnosis for the 79 subjects is presented in Table 3. The true negative and true positive rates were 0.79 and 0.93 , respectively. The false negative rate and false positive rate were 0.17 and 0.09 , respectively. Based on the validation populations, the accuracy of the $7.892 \mathrm{ng} / \mathrm{mL}$ PRG4 cutoff was 0.86 in the COPD subjects.

\section{Correlation between CRP and PRG4}

There was no statistical association between CRP and PRG4 in the COPD patients $(r=0.03, P=0.817)$ (Figure 4$)$. The correlation analysis showed that PRG4 may not be related to systemic inflammation in patients with COPD.

\section{Correlation of CRP and PRG4 with lung function decline}

There were no statistical correlations between CRP levels and 1-year changes in $\mathrm{FEV}_{1} \%\left(R^{2}=0.13, P=0.552\right), \mathrm{FVC} \%$ $\left(R^{2}=0.04, P=0.745\right)$, or $\mathrm{FEV}_{1} / \mathrm{FVC} \%$ of predictive values $\left(R^{2}=0.04, P=0.739\right)$ (Figure 5A). The 1 -year change in predicted $\mathrm{FEV}_{1} \%$ decreased with an increase in PRG4 levels (Figure 5B), but this trend did not reach statistical

Table 3 PRG4 prediction of COPD in 79 subjects

\begin{tabular}{lll}
\hline & PRG4 (ng/mL) & \\
\cline { 2 - 3 } & $\leq \mathbf{7 . 8 9 2}$ & $>\mathbf{7 . 8 9 2}$ \\
\hline Healthy nonsmokers & $0.79(\mathrm{TN})$ & 0.09 (FP) \\
COPD patients & 0.17 (FN) & 0.93 (TP) \\
\hline
\end{tabular}

Note: The cutoff value of $7.892 \mathrm{ng} / \mathrm{mL}$ for PRG4 was used to validate the accuracy of COPD prediction.

Abbreviations: $\mathrm{FN}$, false negative; $\mathrm{FP}$, false positive; TN, true negative; TP, true positive; PRG4, Proteoglycan 4. significance $\left(R^{2}=0.73, P=0.063\right)$. Notably, we observed that the 1-year change in predicted $\mathrm{FVC} \%$ was negatively correlated with the PRG4 level $\left(R^{2}=0.91, P=0.013\right)$. There was no correlation between 1-year changes in predicted $\mathrm{FEV}_{1} /$ $\mathrm{FVC} \%$ and PRG4 $\left(R^{2}=0.05, P=0.725\right)$.

\section{Discussion}

The present study examined biomarkers in the sera of COPD subjects using proteomic approaches. Three major findings are reported: 1) circulating PRG4 (cutoff value of $7.892 \mathrm{ng} / \mathrm{mL}$ ) is a good biomarker for COPD; 2) PRG4 is a marker reflecting pulmonary inflammation in COPD; and 3) PRG4 relates to a 1-year FVC decline in COPD subjects.

The present study identified three biomarker candidates in the serum of healthy controls and in COPD patients with GOLD stages 1,2, 3, and 4 from the biomarker population using a proteomics approach. Sample pooling is a strategy used to minimize individual variation in proteomic studies, ${ }^{16}$ which can help overcome resource constraints when many individuals are analyzed. Type I cytoskeletal 16 keratin and type II cytoskeletal 6A keratin are associated with epithelial tissues from the nail beds,

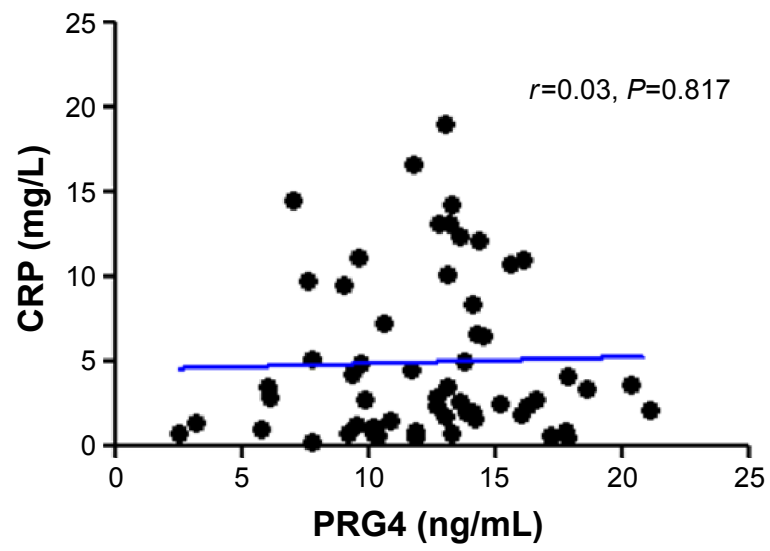

Figure 4 Correlation between CRP and PRG4 in COPD subjects. Abbreviations: CRP, C-reactive protein; PRG4, Proteoglycan 4. 
A a

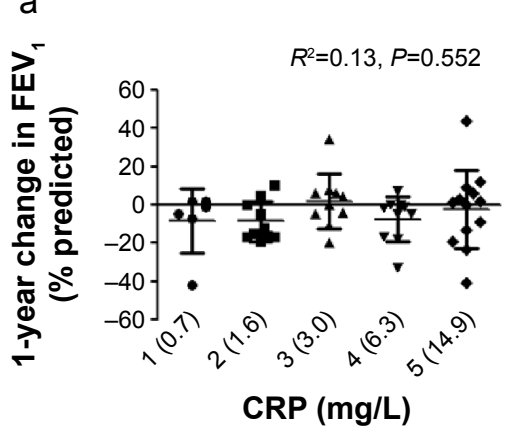

B a

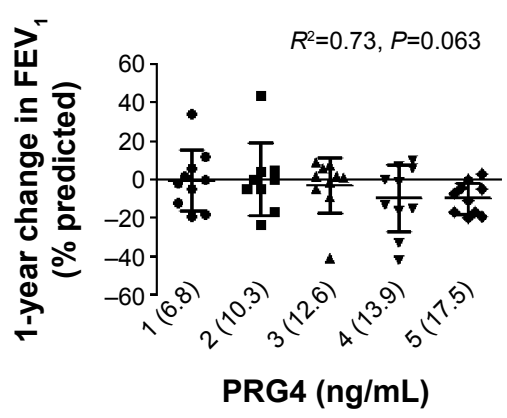

b

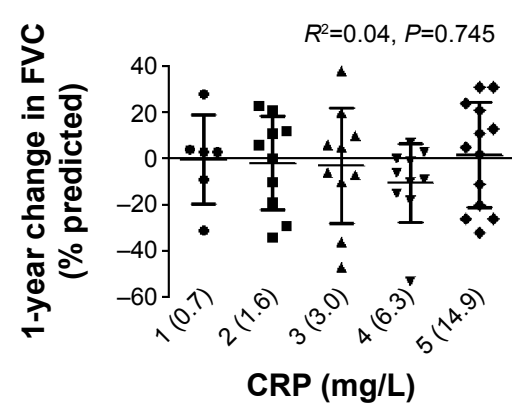

b

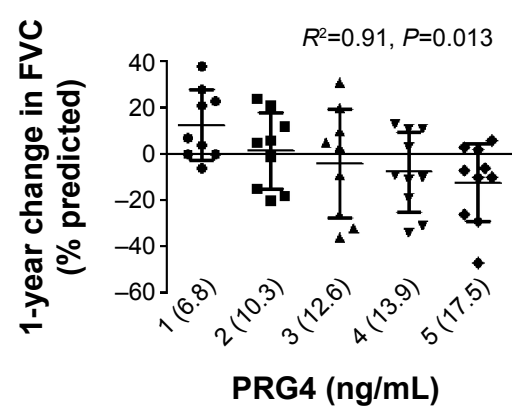

c

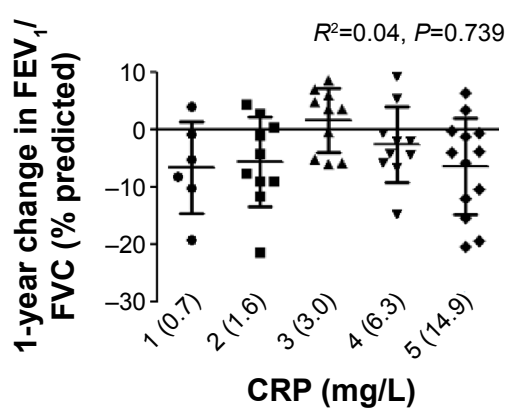

C

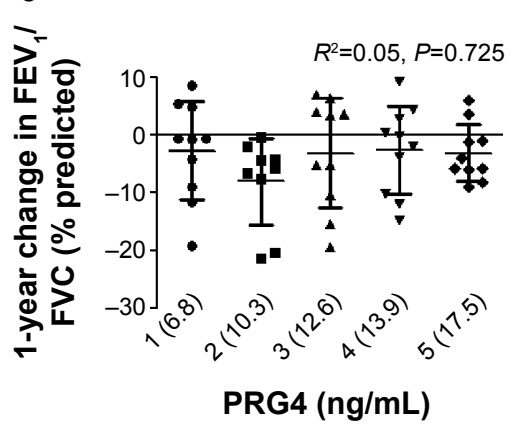

Figure 5 The relationship of serum (A) CRP and (B) PRG4 levels to I-year changes in predictive (a) FEV,\%, (b) FVC\%, and (c) FEV,/FVC\% in COPD.

Notes: The study subjects were divided equally based on quintiles of CRP and PRG4. The values in parentheses on the $\mathrm{x}$-axes represent the mean PRG4 values for each quintile group. Linear regression was used to examine the correlation of quintiles of CRP and PRG4 with I-year changes in FEV, \%, FVC\%, and FEV,/FVC\%.

Abbreviations: $\mathrm{FEV}_{1}$, forced expiratory volume in the first second; FVC, forced vital capacity; CRP, C-reactive protein; PRG4, Proteoglycan 4.

the esophagus, the tongue, and the hair follicles, ${ }^{17,18}$ which are less likely related to the mechanisms of COPD. Consequently, PRG4 was the best potential candidate for a COPD biomarker in the present study. The systemic biomarker CRP was selected as a basis for comparing the PRG4. The COPD subjects had very high levels of CRP in serum samples, but no significant difference was observed when we classified the COPD levels as GOLD stages $1+2$ and $3+4$ in our study. Notably, we observed a very good relationship between serum PRG4 levels and COPD. The subjects in the GOLD stages $3+4$ group had significantly higher PRG4 levels than the subjects in the GOLD stages $1+2$ group. Therefore, PRG4 may differentiate severity in COPD patients, and it can be used to identify COPD severity. A previous study has suggested that CRP is a biomarker for AEs in COPD. ${ }^{2}$ Indeed, we found that CRP levels in patients with COPD with AEs $\geq 1$ were higher than those in COPD patients with AEs $=0$ and in normal subjects. However, CRP levels in a portion of our COPD patients with $\mathrm{AEs} \geq 1$ remained similar to those of COPD patients with AEs $=0$. We found that the COPD subjects with at least one AE had higher PRG4 levels compared with the subjects without AEs, which suggests that an increase in serum PRG4 levels may increase the risk of AEs in patients with COPD.
Increasing efforts are being made in the search for COPD biomarkers. ${ }^{19}$ Eagan et al showed that the plasma levels of neutrophil gelatinase-associated lipocalin are significantly higher in COPD patients compared with healthy control subjects..$^{20}$ Hurst et al identified 36 plasma biomarkers in pairs of stable and exacerbated states from 90 COPD patients. ${ }^{21}$ These authors suggested that CRP was the major biomarker that confirmed COPD exacerbation severity. In the present study, the ROC curve value of PRG4 (area under the curve 0.958) for COPD was much higher than that of CRP (area under the curve 0.8503 from the present study and 0.66 referenced from Eagan et $\mathrm{al}^{20}$ ) and neutrophil gelatinaseassociated lipocalin (area under the curve 0.677). ${ }^{20}$ These comparisons suggest that PRG4 is a potentially sensitive and specific biomarker for COPD. To confirm that PRG4 is a good biomarker for COPD, we recruited the second study population to validate the PRG4 cutoff value derived from the first population (biomarker selection). The accuracy in the validation population was 0.86 , with a false negative rate of 0.17 and a false positive rate of 0.09 , suggesting that circulating PRG4 can discriminate between COPD patients and mainly nonsmoking controls.

Altered chronic inflammation in patients with COPD results from repeated injury and repair and an increased number of inflammatory cell types in the airways, lung 
parenchyma, and pulmonary vasculature. Systemic CRP was compared with PRG4 to evaluate the specific value of PRG4 in patients with COPD. The results showed no correlation between CRP and PRG4, which means that PRG4 may not be involved in the systemic inflammation observed in patients with COPD. Inflammatory responses and a narrowing of peripheral airways lead to reduced $\mathrm{FEV}_{1}$. Parenchymal destruction resulting from emphysema contributes to airflow limitations. ${ }^{22}$ PRG4 was related to 1-year lung function decline values, including 1 -year changes in $\mathrm{FEV}_{1} \%$, $\mathrm{FVC} \%$, and $\mathrm{FEV}_{1} / \mathrm{FVC} \%$ of predicted values. Notably, we found that a 1-year change in the $\mathrm{FVC} \%$ of predicted value was significantly correlated with PRG4 in the COPD patients. This finding implies that PRG4 is a potential biomarker reflecting pulmonary inflammation. However, more evidence is required to verify this correlation.

Breathing is powered by the muscles of the chest wall and the diaphragm, which is the strong muscle that separates the chest from the abdomen. The hallmark of COPD is narrowed bronchial tubes. The lung muscle requires more force to exhale through narrow airways to gain stable oxygen, and the air sacs become hyperinflated (ie, filled with too much air) in emphysema. Repeated high-intensity muscular loading reduces PRG4 concentrations. ${ }^{7}$ The difficulty of muscle movement during breathing could be associated with lung function decline in COPD patients. Additionally, long-term corticosteroid inhalation partially modulated the pulmonary composition of the extracellular matrix, affecting, for example, the level of proteoglycan in moderate-to-severe COPD. ${ }^{23}$ The PRG4 that is lost from the lungs could be transported to the circulatory system and detected as a potential biomarker for COPD. Additionally, PRG4 has been linked to cytokine regulation (IL-1 and TNF- $\alpha$ ) and growth factors (IGF and TGF- $\beta$ ), ${ }^{6}$ which suggests that PRG4 could be associated with pulmonary inflammation. However, further work should be undertaken to investigate the roles of PRG4 in pulmonary inflammation.

\section{Conclusion}

Serum PRG4 is an important biomarker for supporting the COPD diagnosis and relates to the decline in lung function in patients with COPD. Additionally, serum PRG4 is independently related to COPD without systemic oxidative and inflammatory responses. Notably, previous reports showed that the majority of COPD subjects in Taiwan are men $(\sim 95 \%),{ }^{24,25}$ which is consistent with our study. The sex difference should be extrapolated to women with caution. Also, the sample size in the present study was relatively small, particularly in controls. Other lung functions and age-related difference should be discussed in the future. Future in vitro and in vivo studies in humans will provide a greater understanding of the mechanistic principles underlying PRG4 during COPD and novel insights into the role of PRG4 in this devastating disease.

\section{Acknowledgments}

This study was funded by the Ministry of Science and Technology of Taiwan (MOST103-2314-B-038-018, MOST1032314-B-038-066, and MOST102-2314-B-038-055-MY2) and Taipei Medical University (TMU102-AE1-B45).

\section{Author contributions}

All authors contributed substantially to the concept and design of the study, the drafting of the article, and the critical revision of the manuscript for important intellectual content. All authors have read and approved the final version of the paper for publication.

\section{Disclosure}

The authors report no conflicts of interest in this work.

\section{References}

1. Vestbo J, Hurd SS, Agustí AG, et al. Global strategy for the diagnosis, management, and prevention of chronic obstructive pulmonary disease: GOLD executive summary. Am J Respir Crit Care Med. 2013;187: 347-365.

2. Thomsen M, Ingebrigtsen TS, Marott JL, et al. Inflammatory biomarkers and exacerbations in chronic obstructive pulmonary disease. JAMA. 2013;309:2353-2361.

3. Agassandian M, Shurin GV, Ma Y, Shurin MR. C-reactive protein and lung diseases. Int J Biochem Cell Biol. 2014;53:77-88.

4. Palaniyar N, Nadesalingam J, Reid KB. Pulmonary innate immune proteins and receptors that interact with gram-positive bacterial ligands. Immunobiology. 2002;205:575-594.

5. Zbroja-Sontag W. Defense proteins and immune complexes in the blood serum of women with inflammatory and neoplastic lesions of the ovary. Am J Reprod Immunol. 1983;4:11-20.

6. Rees SG, Davies JR, Tudor D, et al. Immunolocalisation and expression of proteoglycan 4 (cartilage superficial zone proteoglycan) in tendon. Matrix Biol. 2002;21:593-602.

7. Abusara Z, Krawetz R, Steele B, DuVall M, Schmidt T, Herzog W. Muscular loading of joints triggers cellular secretion of PRG4 into the joint fluid. J Biomech. 2013;46:1225-1230.

8. Ikegawa S, Sano M, Koshizuka Y, Nakamura Y. Isolation, characterization and mapping of the mouse and human PRG4 (proteoglycan 4) genes. Cytogenet Cell Genet. 2000;90:291-297.

9. Liu YJ, Lu SH, Xu B, et al. Hemangiopoietin, a novel human growth factor for the primitive cells of both hematopoietic and endothelial cell lineages. Blood. 2004;103:4449-4456.

10. Su JL, Schumacher BL, Lindley KM, et al. Detection of superficial zone protein in human and animal body fluids by cross-species monoclonal antibodies specific to superficial zone protein. Hybridoma. 2001;20: 149-157.

11. Hardingham TE, Fosang AJ. Proteoglycans: many forms and many functions. FASEB J. 1992;6:861-870. 
12. Hallgren O, Nihlberg K, Dahlbäck M, et al. Altered fibroblast proteoglycan production in COPD. Respir Res. 2010;11:55.

13. Frevert CW, Sannes PL. Matrix proteoglycans as effector molecules for epithelial cell function. Eur Respir Rev. 2005;14:137-144.

14. Yu CJ, Wang CL, Wang CI, et al. Comprehensive proteome analysis of malignant pleural effusion for lung cancer biomarker discovery by using multidimensional protein identification technology. J Proteome Res. 2011;10:4671-4682.

15. Su CL, Chen TT, Chang CC, et al; Taiwan CardioPulmonary Research Group (T-CPR). Comparative proteomics of inhaled silver nanoparticles in healthy and allergen provoked mice. Int J Nanomedicine. 2013; 8:2783-2799.

16. Diz AP, Truebano M, Skibinski DO. The consequences of sample pooling in proteomics: an empirical study. Electrophoresis. 2009;30: 2967-2975.

17. Rosenberg M, Fuchs E, Le Beau MM, Eddy RL, Shows TB. Three epidermal and one simple epithelial type II keratin genes map to human chromosome 12. Cytogenet Cell Genet. 1991;57:33-38.

18. Schweizer J, Bowden PE, Coulombe PA, et al. New consensus nomenclature for mammalian keratins. J Cell Biol. 2006;174:169-174.

19. Sin DD, Hollander Z, DeMarco ML, McManus BM, Ng RT. Biomarker development for COPD: from discovery to clinical implementation. Am J Respir Crit Care Med. Epub 2015 Jul 15.
20. Eagan TM, Damås JK, Ueland T, et al. Neutrophil gelatinase-associated lipocalin: a biomarker in COPD. Chest. 2010;138:888-895.

21. Hurst JR, Donaldson GC, Perera WR, et al. Use of plasma biomarkers at exacerbation of chronic obstructive pulmonary disease. Am J Respir Crit Care Med. 2006;174:867-874.

22. Hogg JC, Chu F, Utokaparch S, et al. The nature of small-airway obstruction in chronic obstructive pulmonary disease. $N$ Engl J Med. 2004;350:2645-2653.

23. Kunz LI, Strebus J, Budulac SE, et al; GLUCOLD (Groningen Leiden Universities Corticosteroids in Obstructive Lung Disease) Study Group. Inhaled steroids modulate extracellular matrix composition in bronchial biopsies of COPD patients: a randomized, controlled trial. PLoS One. 2013;8:e63430.

24. Ahamed M, Alhadlaq HA. Nickel nanoparticle-induced dose-dependent cyto-genotoxicity in human breast carcinoma MCF-7 cells. Onco Targets Ther. 2014;7:269-280.

25. Chen CZ, Wang LY, Ou CY, Lee CH, Lin CC, Hsiue TR. Using cluster analysis to identify phenotypes and validation of mortality in men with COPD. Lung. 2014;192:889-896.
International Journal of COPD

\section{Publish your work in this journal}

The International Journal of COPD is an international, peer-reviewed journal of therapeutics and pharmacology focusing on concise rapid reporting of clinical studies and reviews in COPD. Special focus is given to the pathophysiological processes underlying the disease, intervention programs, patient focused education, and self management protocols.

\section{Dovepress}

This journal is indexed on PubMed Central, MedLine and CAS. The manuscript management system is completely online and includes a very quick and fair peer-review system, which is all easy to use. Visit http://www.dovepress.com/testimonials.php to read real quotes from published authors.

Submit your manuscript here: http://www.dovepress.com/international-journal-of-chronic-obstructive-pulmonary-disease-journal 